\title{
Consideraciones sobre la literatura infantil y juvenil. Literatura y subliteratura
}

\author{
Pablo LORENTE MUÑOZ \\ Cuerpo de Secundaria. Gobierno de Aragón \\ lorentepablo@hotmail.com
}

Recibido: septiembre 2010

Aceptado: marzo 2011

\section{RESUMEN}

Que la Literatura Infantil y Juvenil (LIJ) ocupa un lugar importante en la formación de los alumnos de las enseñanzas básicas y medias es algo incuestionable. Sin embargo, la consideración de esta literatura es un factor mucho menos claro. En este debate, interviene con fuerza la noción de canon y cómo este canon institucionalizado a través de las leyes educativas, obliga a tratar unos ciertos temas y a leer unas ciertas obras que no tienen por qué coincidir con otro gran propósito del sistema educativo: el fomento de la lectura. En este trabajo, analizamos las relaciones entre el canon y la LIJ, observar su espacio, es decir, su naturaleza como literatura o subliteratura y ver cómo se posiciona esta literatura con sus peculiares características dentro del sistema educativo.

Palabras clave: Literatura infantil y juvenil, LIJ, canon, educación.

\section{Considérations sur la littérature d'enfance et de jeunesse. Littérature ou sous-littérature}

\section{RÉSUMÉ}

Que la littérature d'enfance et de jeunesse occupe une place importante dans la formation des étudiants dans l'enseignement primaire et secondaire est incontestable. Toutefois, la considération de cette littérature est beaucoup moins claire. Dans ce débat, il est vigoureusement mise en cause la notion de canon et comment ce canon, institutionnalisée à travers des lois sur l'éducation, oblige à traiter certains sujets et à lire certaines œuvres qui n'ont pas à coïncider avec un autre objectif majeur du système éducatif : la promotion de la lecture. Dans cet article, nous analysons la relation entre canon et Littérature d'enfance et jeunesse, voire son espace, c'est-à-dire, sa nature en tant que littérature ou sous-littérature et constater comment cette littérature avec ses caractéristiques distinctives se place au sein du système éducatif.

Mots-clés : Littérature d'enfance et de jeunesse, canon, éducation. 
Some thoughts on Children's and Youth Literature: Literature and Subliterature

\begin{abstract}
That the Children's Literature occupies an important place in the training of students in primary and secondary education is unquestionable. However, the consideration of this kind of literature is a much less clear factor. In this debate, the notion of canon is vigorously involved and how this canon institutionalized through educative laws, forces the treatment of certain topics and the reading of some works that do not have to coincide with other major purpose of the educative system: the building reading. In this paper, we analyze the relationship between canon and the literature of children and the youth, observe its space, that is, its nature as literature or sub-literature and examine how this literature gets its place with its distinctive features within the educative system.
\end{abstract}

Keywords: Literature of children and the youth, canon, education.

SUMARIO: 1. Introducción. 2. El canon. 2.1. El canon y la Literatura infantil y juvenil. 3. Literatura y subliteratura. 3.1. La razón de ser de la LIJ. Características. 5. Conclusiones. Referencias bibliográficas.

\title{
1. INTRODUCCIÓN
}

Se da la paradójica situación de que un profesor de Lengua castellana y Literatura que imparta clase en el primer y el segundo ciclo de la ESO, normalmente un Licenciado en Filología Hispánica, no ha cursado, en principio, ninguna materia de Didáctica de la Lengua y la Literatura -los nuevos planes de estudio de la Facultad de Filosofía y Letras de la Universidad de Zaragoza para la titulación arriba mencionada siguen sin contemplar ninguna materia de este estilo; en teoría, el nuevo Máster en Formación del Profesorado podrá paliar esta laguna, pues depende de la Facultad de Educación-. Así pues, este futuro profesor se encontrará en su tarea docente con varias dificultades. Por un lado, con una profunda incomprensión del contexto al que se va a enfrentar, por otro, con una sólida formación filológica que, a priori, sólo le va a resultar de una cierta utilidad a la hora de dirigirse a su alumnado, lo explicita Mendoza (1998, 193-194):

La crítica sociológica se ocupa de detectar el modelo social y sistema de valores recogidos en la LIJ, y de señalar como el probará su constante presencia en el área de lenguaje y en otras. Es, pues, inexcusable que el futuro profesor que se está formando en didáctica de la lengua y la literatura tenga un conocimiento de la LIJ en todas sus manifestaciones, problemas y posibilidades de explotación (López Valero, 1992; Mendoza 1994 b).

Este problema viene de lejos, podemos señalar un artículo de El País de fecha 11 de diciembre de 2006, donde se pone de manifiesto la necesidad de hacer que los 
alumnos de cualquier edad lean más y mejor, según sus gustos y necesidades. Se incide en la inclusión de nuevas obras en el currículo de los alumnos pero también, en la formación de profesores, proponiendo que en el "tradicional" mundo de las filologías se establezcan cambios ${ }^{1}$ para que tanto maestros y profesores conozcan las "otras" obras, aquellas que pueden interesar más a nuestros alumnos:

\section{Los especialistas piden incluir la literatura juvenil en la formación de los profesores}

No basta con leer: hay que saber qué y cómo se lee. Pero a los maestros y profesores no se les forma adecuadamente para que transmitan a sus alumnos las recetas adecuadas. Los maestros de los niños más pequeños reciben clases de literatura infantil y juvenil; pero la materia es sólo voluntaria para los futuros docentes de primaria y prácticamente inexistente en las enseñanzas universitarias para los que serán profesores de instituto. Y la adolescencia es una etapa clave para consolidar el amor por la lectura entre los alumnos. Por estas y otras razones, la Asociación Española de Amigos del Libro Infantil y Juvenil ha solicitado al Ministerio de Educación que aproveche la actual reestructuración de las carreras para incluir la asignatura de forma obligatoria en la carrera de maestro de primaria y en las filologías.

Así que el profesor debe enfrentarse en las aulas a un doble reto. El primero es cumplir un currículo determinado que se debe mantener dentro de los márgenes del canon (ahora nos ocuparemos brevemente de este tema). El segundo reto es hacer todo lo posible para cumplir una de las grandes expectativas de los planes educativos, que es el fomento de la lectura, una tarea compleja. Por ejemplo, así se expone en el currículo de la Comunidad Autónoma de Aragón (contextualización de la Ley Orgánica 3 de mayo de Educación, LOE) en los objetivos generales de la ESO²:

Con el fin de promover las medidas necesarias para que en las distintas materias se desarrollen actividades que estimulen el interés y el hábito por la lectura y la expresión oral, se incluirán en el Proyecto curricular estrategias de intervención educativa para la mejora de la comprensión y expresión oral y escrita.

Que la lectura es beneficiosa para nuestros alumnos queda fuera de este debate, que se debe centrar en cómo animar a nuestros alumnos a que lean fuera de la obligatoriedad de las materias, teniendo en cuenta una serie de obstáculos de fondo: poco interés por la lectura, tiempo de ocio que poco o nada tiene que ver con el libro (cine, vídeo juegos...), brevedad del curso escolar, tiempo limitado por la enorme

${ }^{1}$ En línea:

http://www.elpais.com/articulo/educacion/especialistas/piden/incluir/literatura/juvenil/formaci on/profesores/elpepusocedu/20061211elpepiedu_9/Tes [Consultado: 11/12/2006].

${ }^{2}$ Orden 9 de mayo de 2007:

http://www.educaragon.org/files/Orden\%20curr\%C3\%ADculo\%20Primaria.pdf 
variedad de materias y, fundamentalmente, cumplimiento del currículo para cada curso.

Los especialistas afirman que la lectura se debe adaptar a las necesidades, gustos e intereses de los alumnos, lo que en muchas ocasiones, choca frontalmente con la distribución de los currículos para los cursos de ESO, un caso especialmente notable es el currículo para $3^{\circ}$ de ESO, donde los alumnos pasan de una serie de generalidades sobre la literatura a un programa histórico muy concreto que más tarde reproducimos. En este sentido, y refiriéndose a la biblioteca de aula, encontramos una valiosa reflexión sobre la selección de materiales de lectura para los alumnos, reflexión que puede ser válida también en cualquier momento:

La selección será hecha por nosotros, una vez conocidos los niños y de acuerdo con sus capacidades e intereses, ante las experiencias no completamente positivas de las selecciones llevadas a cabo de manera oficial (Carlson, 1989; Lorite, 1989). Es muy importante proporcionar el material adecuado, ya que cuando determinado lector encuentra el libro correcto en el momento preciso, esto puede provocar un choque de conocimiento (Tucker, 1985, p. 319), mientras que en el caso contrario puede producir una sensación de fracaso y de frustración con serias consecuencias para experiencias posteriores. (Cerrillo y García Padrino, 1996, 76)

Varias soluciones se han propuesto para intentar paliar el problema, una de ellas es hacer de las lecturas "obligatorias" un fenómeno más entretenido, en ocasiones, haciendo de los clásicos que los alumnos deben conocer porque así lo indican las leyes educativas (El Quijote, La Celestina, Lazarillo de Tormes, Galdós, Bécquer...) unos libros más atractivos. Son las ediciones versionadas que, en algunos casos, acaban convirtiendo los clásicos en meros tebeos. Otra solución, muy a pesar de Ítalo Calvino, puede ser el no leer los clásicos para leer otro tipo de literatura, más actual, más acordes con nuestros tiempos, en la gran mayoría de los casos, libros de Literatura Infantil y Juvenil (LIJ). Ahora bien, entonces ¿qué condición otorgamos a esta literatura?

\section{EL CANON}

El debate del canon tiene una gran importancia, por ejemplo, en Estados Unidos. El canon no sólo se discute, sino que también se contesta. Una de estas contestaciones, ha sido la creación y aparición de infinitos acercamientos a la literatura y a todas las formas culturales derivadas (lo que se ha denominado en el mundo anglosajón Cultural Studies) desde los más variopintos prismas que, a su vez, han pretendido generar otros cánones.

El canon está íntimamente unido a la Historia Literaria puesto que ésta no hace otra cosa que tratar las obras seleccionadas y, en muchos casos, seleccionarlas a su vez. A través del tiempo, y por diferentes razones, unas obras han destacado por encima de otras y se han perpetuado en nuestros manuales e historias literarias. 
El término de canon ya era utilizado por los filólogos alejandrinos para referirse a una lista de obras escogidas y dignas de imitación. Más ampliamente, el canon literario es la "lista o elenco de obras consideradas valiosas y dignas por ello de ser estudiadas y comentadas" (Sulla, 1998, 11). Estas obras, el canon, tienen varias funciones muy bien determinadas, desde el punto de vista estético, la principal es que sirven para promover modelos, ideas e inspiraciones. Sin embargo, el canon no es casual, hay que pensar en quién hace esa selección, a quién le pertenece esa "elección de libros por parte de nuestras instituciones de enseñanza" (Bloom, 1995, 25). El canon es, por tanto, el representante de un valor buscado por las instituciones que lo eligen, lo que lo entroncaría con la Historia imperante, que no es otra que la política.

El valor imperante en la Edad Moderna -en gran medida y sin entrar en el debate sobre el posmodernismo, la nuestra- sería aquél que va en beneficio de la construcción de una idea de nación, de ahí la necesidad de marcar unas obras que respondieran a esta formación, que es, en primer término, formación lingüística para producir una unidad territorial, económica y, al fin, de identidad. Bloom, en su obra El canon de occidente, sin embargo, parece tener una idea más idealista sobre la formación de este canon, en primer lugar, se nos dice que no hay ninguna marca de comunidad en este canon: "La manera más estúpida de defender el canon occidental consiste en insistir en que encarna las siete virtudes morales que componen nuestra supuesta gama de valores normativos y principios democráticos" (Bloom, 1995, 30).

Para Bloom, la idea del canon es poco política, puesto que enaltece los valores estéticos de las obras que pudieran formar parte de este conjunto por delante de otras: "El canon existe precisamente con el fin de imponer límites, de establecer un patrón de medida que no es en absoluto político o moral" (Íbid: 32). Así pues, el canon no sólo carecería de valores políticos sino también morales, el canon no es educativo, sería puramente estético, idea con la que difícilmente podemos estar de acuerdo. Esta concepción estética dejaría de lado ideas tan claramente establecidas en el canon como la transmisión de una herencia intelectual o la de creación de una serie de marcos de referencia comunes (identidad) entre los miembros hacia los que ese legado cultural y de tradición están destinados.

La obra de Bloom, como no puede ser de otro modo, es parcial, en ella realiza una lista no exhaustiva sobre la literatura occidental, incluye a veintiséis escritores: Chaucer, Cervantes, Montaigne, Shakespeare, Goethe, Dickens, Joyce, Proust... y trata de averiguar qué los convierte en canónicos y por qué (Bloom, 1995, 33): "La respuesta, en casi todos los casos, ha resultado ser la extrañeza, una forma de originalidad que o bien no puede ser asimilada o bien nos asimila de tal modo que dejamos de verla como extraña" ese patrón de medida sería así "un signo de originalidad capaz de otorgar el estatus canónico a una obra literaria, es esa extrañeza que nunca acabamos de asimilar, o que se convierte en algo tan asumido que permanecemos ciegos a sus características".

Si nos vamos hacia un terreno más práctico, los profesores de enseñanzas medias estamos sujetos a un canon. Basta con abrir un manual por el índice para que quede bien claro: una serie de autores y obras imprescindibles para comprender nuestra cultura, dominar nuestra lengua, comprender nuestra historia etc. El problema es que, 
si bien el conocimiento de esta selección es algo imprescindible, es también una limitación, en el sentido de que esta selección es de obligado cumplimiento. Este canon tiene una importancia capital, pervive y pasa a quedar impreso en un currículo anual de enseñanzas medias o de programas docentes en las Universidades. Además, para su cumplimiento tenemos asignadas un número de horas concreto. Hasta tal punto que el canon, a través de este mecanismo institucionalizado, pervive y acaba siendo el único protagonista (salvo contadas excepciones) de la formación de estudiantes y expertos.

Sin embargo, nosotros como profesores, que en el fondo, estamos velando, por obligación, formación o convencimiento, por el mantenimiento de este canon, en muchas ocasiones acudimos a otro tipo de literatura, es decir, a la Literatura Infantil y Juvenil. Y es que numerosas voces se han alzado contra el canon, por ejemplo, en relación con la poesía realizada por mujeres, $\operatorname{Rosal}(2008,79)$ incide en la necesidad de:

Revisar y redefinir el canon con un criterio amplio y no reductor, suscribiendo la idea de la importancia de la toma de conciencia por parte de las propias mujeres profesionales de la literatura y de la enseñanza de reivindicar justicia e igualdad de oportunidades en la construcción del canon.

En esta misma línea se ha pronunciado Mendoza, para insistir en el conflicto que supone el canon implementado en los currículos de secundaria y la realidad de las aulas, los alumnos en último término.

Hay divergencias entre los materiales literarios de comprobada eficacia formativa y los cánones académico-filológicos. Esta divergencia es la causa de que, con frecuencia, el empleo de la LIJ se articule en un canon oculto, que aflora en las actividades de aula preparadas y previstas por el profesor. Este canon oculto, sin embargo, se diluye sin dejar rastros de un empleo sistematizado de la LIJ, porque en la programación oficial cede su espacio a las obras que integran al canon definido en el currículum oficial. (Mendoza, 2000)

Siguiendo esta lógica, propone la revisión del canon, estableciendo a su vez, varios tipos de canon. Por un lado, señala el "canon filológico" del que ya nos hemos ocupado, por otro, el "escolar", basado en las obras de LIJ y que aportaría ejemplos sobre tipologías textuales, modelos de construcción narrativa etc. Añade, además, el canon de aula (los ejemplos a trabajar en la misma), el canon formativo (combinación de los anteriores) y la unión de todos ellos, que sería "el canon para desarrollar una básica competencia literaria”.

En suma, la clave de la eficacia del canon escolar en la formación de la competencia literaria radica en la diversificada ejemplaridad de las muestras literarias que lo integren, así como en las actividades de observación de las convenciones estéticas, de rasgos del código oral y del código escrito y, de manera más genérica, de la formación cultural diversificada que pueden aportar (Mendoza, 2000) 
De un modo u otro, creo que la gran mayoría de los profesores, integran este tipo de prácticas en la función docente de modo normal, no puede ser de otro modo ya que uno de los fines -entre los muchos que se indican en los diversos currículos- que se persiguen en la materia de Lengua y Literatura es la "educación literaria", integrando por tanto, diversos materiales y escuchando o intentándolo al menos, a nuestros alumnos.

Mendoza (2000) llama a estas prácticas nuevos cánones y éstos servirían para:

a. estructurar los contenidos curriculares de modo significativo y pragmático;

b. adecuar los nuevos objetivos de formación a los intereses del lector y a las necesidades de formación de los alumnos como lectores competentes; y

c. reubicar los conocimientos historicistas, culturales en la línea enciclopédica o de inconcretas descripciones metaliterarias.

Sin embargo, y bajo mi punto de vista, creo que se equivoca Mendoza al proponer un nuevo canon, ya que si algo caracteriza al canon es su inmutabilidad, estar fijado, anclado en el imaginario colectivo y en la formación cultural de generaciones y generaciones, bajo los principios de unión cultural y lingüística, esto es, territorial e identitaria. Además, parece que el debate debe ser otro, ya que lo que se pone en tela de juicio no es el canon en sí, sino la idoneidad de los contenidos que se deben impartir en la ESO, discutiendo que sean éstos y no otros. Por ejemplo, vamos a observar los contenidos del bloque de Educación Literaria para $3^{\circ}$ de ESO en el currículo aragonés para comprobar, de nuevo, el peso del canon. De tal modo, veremos que a lo que se refiere Mendoza con el otro canon, sólo tendría cabida en el último punto. Mejor dicho, que otro tipo de literatura, la LIJ por ejemplo, sólo se contempla, de modo muy indirecto en este último punto:

- Identificación en textos de las relaciones entre forma y contenido y de las características de la función poética, con especial atención a los recursos retóricos del plano fónico, como onomatopeya, aliteración, paronomasia; del plano morfosintáctico, como paralelismo e hipérbaton, y del plano semántico, como paradoja, alegoría y símbolo.

- Lectura de obras o fragmentos adecuados a la edad, relacionándolos con los grandes períodos y autores de la literatura española, con atención específica a la aragonesa, desde la Edad Media hasta el siglo XVIII, prestando atención a la estructura, género y estilo y a la relación de la obra con la propia experiencia y con el contexto que los ha generado.

- Lectura comentada y recitado de poemas, comparando el tratamiento de ciertos temas recurrentes, en distintos períodos literarios, y valorando la función de los elementos simbólicos y de los recursos retóricos y métricos en el poema (técnicas de comentario de texto).

- Lectura comentada de relatos, observando la transformación de la narrativa desde la épica medieval en verso a la narración moderna en prosa, y del héroe al personaje de novela (técnicas de comentario de texto). 
- Lectura comentada y dramatizada de obras teatrales breves y fragmentos representativos del teatro clásico español, reconociendo algunas características temáticas y formales (técnicas de comentario de texto).

- Conocimiento de las características generales de los grandes períodos de la historia de la literatura oral y escrita, culta y popular, desde la Edad Media hasta el siglo XVIII, y acercamiento a algunos autores relevantes de la literatura española, de los que algunos podrán ser aragoneses (como la literatura popular, Baltasar Gracián o el pensamiento ilustrado en Aragón) por medio de las lecturas personales y comentadas.

- Composición de textos de intención literaria y elaboración de trabajos sencillos sobre lecturas.

- Utilización progresivamente autónoma de la biblioteca del centro, de las del entorno y de bibliotecas virtuales.

- Desarrollo de la autonomía lectora y aprecio por la literatura como fuente de placer, de conocimiento de otros mundos, tiempos y culturas.

En definitiva, podemos escapar al canon, rodearlo, engañarlo, los profesores, todavía, tenemos un cierto margen de libertad, pero eso que hagamos ya no será el canon, será otra cosa.

\subsection{El canon de la literatura infantil y juvenil}

Los intentos por realizar un canon de la LIJ han sido abundantes en los últimos años, en un intento de ordenar y organizar la enorme, y por otra parte reciente, creación de obras dirigidas a este tipo de público. En el fondo, este intento, no es sino otro síntoma de su apartamiento del mundo oficial, señal también, de su lucha por establecer su propia identidad y ser aceptada tal y como es, defendiendo sus valores literarios, formativos y educativo. Pero ese supuesto canon, no es el canon, es una selección, una antología, otra cosa, ¿útil? Por supuesto que sí, también, muy necesaria.

No existe hoy por hoy un canon literario infantil y juvenil plenamente aceptado. Pero sí son muchos y variados algunos acercamientos tan oportunos como controvertidos. Entre ellos, podemos considerar las diversas selecciones y guías realizadas de forma individual o colectiva que se proponen por parte de especialistas y profesionales que, aunque nunca se erigen como canon, se presentan como una tarea crítica destinada a la orientación de los diversos agentes mediadores entre la literatura y los niños. Cabe mencionar de pasada, entre tantas, la labor continuada del Seminario de Bibliografía de la Asociación Rosa Sensat, que puede consultarse en diferentes formatos, incluido Internet, la selección de 1000 libros de la FGSRP (1997), el libro-guía del Equipo Peonza Un libro para leer muchos más (1993), los diccionarios de autores y obras realizados por Luis Daniel González (2001, 2002); el canon de literatura infantil española 100 obras de literatura infantil del siglo XX (2000) y el canon de literatura infantil universal anterior al siglo XX de Harold Bloom Relatos y poemas para niños extremadamente inteligentes de todas las edades (2003) que, no así ninguno de los anteriormente citados, incluye los numerosos textos seleccionados por este afamado 
crítico, a la manera de las primeras antologías que se realizaron de literatura infantil y juvenil de la mano de Carmen Bravo Villasante (1966, 1973, 1988).

La última propuesta Cien libros para un siglo pertenece al Equipo Peonza (2004). Aborda el siglo XX a través de los comentarios de las 100 obras que considera más representativas en cada uno de sus cien años. Vamos a detenernos extensamente en su contenido. (Tejerina, 2004)

Observando la variedad de propuestas de las que nos informa Tejerina, podemos estar de acuerdo en que el canon de la LIJ no existe, ya que una de sus características es la fijación. La suposición es que el canon de esta literatura no existirá hasta dentro de mucho tiempo, por un lado, como razones principales podemos señalar que esta literatura no recibe una adecuada atención, es decir, la crítica general apenas se encarga de ella. Además, nunca ha estado incluida dentro del principal marco canónico, la Historia de la Literatura, si acaso, esa historia se debiera a empezar a realizar poco a poco, y es que sin Historia literaria, no podemos hablar de canon. Otra razón secundaria si acaso pero importante, es que la mayor parte de la producción de LIJ es reciente, por tanto, no va a entrar en ningún supuesto canon, ya que una de las razones para incluir a una obra en este canon, es que haya pasado el tiempo suficiente para que una obra sea percibida por las instituciones como importante o esencial.

Observada esta problemática, surgen numerosas cuestiones, si la LIJ no es una literatura canónica y, por tanto, apenas tiene cabida en la oficialidad del mundo de la enseñanza ¿cómo es que numerosos profesores indican a sus alumnos que lean este tipo de obras? La respuesta proviene de la propia institución, que indica que una de sus prioridades es el fomento de la lectura, ahora bien, ¿qué valor atribuimos a esta literatura?

\section{LITERATURA Y SUBLITERATURA}

Las formas literarias de la LIJ de las que nos ocupamos -en estas páginas vamos a hablar de formas novelísticas fundamentalmente-, en principio, no tienen permitido el acceso al canon. La "gran" literatura, la alta cultura, se enfrenta de modo continuo a otras formas de menos prestigio, menores o que se consideran directamente "subliteratura". Sabemos que definir el concepto de literatura es complejo, sobre todo cuando intervienen las ideologías -esto es, siempre y cuando la estética no se encuentre presente en el debate-, así, si pensamos en la obra de Sartre Qu'est-ce que la litterature?, obtenemos una respuesta bastante divergente a la que nos da Estébanez Calderón en su Diccionario de términos literarios o a Cabesa (2009):

Según la Enciclopedia Sopena, la literatura es el género "cuyo fin es la belleza por medio de la palabra". La definición nos obliga a pensar que "literatura" es la que se refiere a las "grandes obras", o sea, que por su expresión y su estructura poseen un valor estético unido a una "altura intelectual general"; si alguna obra carece de los valores referidos nos vemos en la obligación de de pensar en ella como "subliteratura". 
Como vemos, la noción de subliteratura tiene mucho de peyorativo, sin embargo, tras la definición estética, nos queda un resquicio, si acaso para la función que cumple esta literatura. Siguiendo con la observación y diferenciación entre literatura y subliteratura, presentamos a continuación una serie de características de este último término para observar si podemos detectar en la LIJ estos rasgos:

La literatura es un arte que presenta los muy diversos sentimientos y pasiones del ser humano, con toda la fuerza y la intensidad que concede el poder de la palabra escrita. La subliteratura, en cambio, está formada de clichés y lugares comunes: las historias se repiten constantemente, pues van dirigidas al sentimentalismo vulgar del lector.

La subliteratura está concebida para sectores que no tienen una espiritualidad educada y se conforman con cartabones o modelos reiterativos de elementales historias de amor, por ejemplo. Éstas se caracterizan por un contexto de orden melodramático en el que los personajes aludidos son tipos caracterológicos que no tiene personalidades relevantes, de acuerdo con una verdadera psicología humana. De esta manera, siempre se encuentra la muchacha incauta, la intrigante enemiga, el galán pérfido, el príncipe azul, la madre inquisitiva, la anciana comprensiva y el infortunio general.

En la verdadera literatura, las personalidades humanas superan estos esquemas para combinar las muy distintas facetas que conforman o que pueden conformar al ser humano. La historia literaria que en ella se cuenta busca la originalidad y no la repetición infinita de una forma temática.

La subliteratura siempre presenta lo mismo: la literatura es original en el tratamiento de sus temas. La subliteratura puede contar una historia de amor, de aventura o, simplemente, cómica, que busca distraer superficialmente al lector poco entrenado; la literatura es un testimonio del hombre y de la sociedad que la produce. La subliteratura es un fácil alimento para el alma humana, en el que no se advierte el seguimiento de las grandes instituciones sociales; la gran literatura siempre nos da el testimonio de la evolución misma de las sociedades con un sentido crítico (Correa y Orozco, 2004, 17-18)

Teniendo en cuenta esta definición, nos enfrentamos a un doble problema, por un lado, realizar una consideración estética de la LIJ, por otro, plantear, aún en el caso de que se tratara de subliteratura, cuál es su utilidad en nuestra función docente. Si dejamos de lado los grandes problemas críticos y estéticos que envuelven a la literatura y hablamos de literatura como producto de consumo y de entretenimiento, una ficción que nos hace disfrutar, pensar, sentir o emocionarnos, de literatura como placer en resumidas cuentas (y en este apartado debemos incluir la novela histórica, romántica, rosa y otras muchas), no podemos pensar que es algo menos que otras producciones, de ser así, no hacemos otra cosa que seguir elitizando la literatura, y alejando el mundo de la crítica de la gran mayoría del público, el consumidor al fin y al cabo. También es cierto que no podemos desdeñar el canon, lo canónico, no lo pueden hacer los profesores con sus programas, por ejemplo, pero sí podemos encontrar resquicios para abrir el abanico de posibilidades como ya hemos señalado.

Para demostrar el poder del canon, podemos señalar varios ejemplos. El lunes 8 de enero de 2007, el periódico ADN de Sevilla, publicó una entrevista al escritor Felipe Benítez Reyes, a la sazón, ganador del premio Nadal con su obra Mercado de 
espejismos. Esta obra, es una parodia de los libros de intriga esotérica al estilo de $E l$ código Da Vinci, que tanto éxito de ventas ha tenido en nuestro país. Al referirse a este tipo de libros, el entrevistado nos dice:

Esta es una novela de grandes farsantes. No hace falta nombrarlos para saber de quienes estamos hablando. Pero yo no soy un purista, no estoy en contra de estas obras de consumo y lectura fácil. La subliteratura tiene un lugar y cumple una función.

En estas palabras se condensa el sentimiento de adoración hacia el canon y su enorme fuerza como autoridad, así como el consiguiente desprecio hacia las formas "menores" de cultura. Según sus palabras, las obras de consumo -lo cual es bastante vago puesto que en último término todo escritor quiere que su obra se lea y por tanto, se venda- no merecen su aprobación, es más, si son de lectura fácil, es señal de su falta de calidad, y son denominadas, simplemente, como algo por debajo de la literatura.

Si las analizamos como críticos, quizá pudiéramos estar de acuerdo, pero como profesor, sigo maravillado con el papel jugado por un libro como El Código Da Vinci, por la simple razón de que en su momento logró que mucha gente que no tenía esa costumbre, hablara de un libro, se lo prestaran, de que gente muy poco aficionada a la lectura leyera, con interés, con gusto. ¿Acaso esto no tiene mérito? También lo tiene, y mucho, la polémica derivada de él, porque consiguió que mucha gente se planteara conceptos literarios e históricos. Hay que añadir, además, que dejó una prueba evidente de que la mayoría de la población no sabe leer, embaucada por una historicidad que no se puede otorgar a una obra literaria, que sólo es literaria por la ficcionalidad de la misma.

Como defensor de la lectura como piedra angular de la educación, destaca la opinión de Víctor Moreno que propone otorgar la palabra a los niños para que opinen sobre lo que los adultos escriben para ellos (2003: 34). Sin embargo, y siendo más realistas, parece adecuado formular una serie de rasgos para seleccionar estas obras que se pueden adecuar a nuestros alumnos. Los rasgos más importantes a tener en cuenta para la elección de una obra y no de otra parecen ser según el mismo autor:

- "Que el tema que trata la obra se ajuste a los intereses del potencial lector".

- "Que el lector se identifique con los personajes para que lectura resulte más placentera". Este criterio puede parecer aleatorio, sin embargo, en el estudio sobre "Lectores y lecturas ESO" (Tejerina: 2004), el porcentaje en las votaciones sobre libros que trataban la temática de "protagonistas y temas de mi edad" es con creces superior a cualquier otra.

- "Que el libro contenga un modelo lingüístico adecuado para el aprendizaje de los alumnos", en este caso podemos observar de nuevo el criterio de autoridad pues debe ser un adulto, profesor en el caso que nos ocupa, el que seleccione lo que se supone que los alumnos deben aprender.

- "Que sean estéticamente adecuados", dicho de otro modo, algo tan subjetivo como que "estén bien escritos" o que tengan un cierto nivel literario. 
Para Teresa Colomer, cuatro serían los aspectos fundamentales a tener en cuenta cuando hablamos de LIJ: "la calidad literaria, los valores educativos, la opinión y el gusto de los niños y jóvenes y el itinerario de aprendizaje literario" (2002: 8-17).

Para Cerrillo (2007:71) serían tres estos aspectos: "La calidad literaria de los textos, la adecuación de las obras a los intereses y gustos de los lectores y la capacidad de las obras seleccionadas para contribuir a la adquisición de la competencia literaria de los lectores".

Entonces, ¿la LIJ qué es? Parece claro y es lo que estamos intentando dilucidar, que no es alta literatura puesto que no convive con ese tipo de literatura en ningún espacio. Por ejemplo, existe un Premio Nacional de Literatura Infantil y Juvenil; en los suplementos culturales cuenta con un espacio bien diferenciado o, simplemente, no se habla de ella; en las bibliotecas y librerías se ordena en un espacio distinto, las colecciones de las editoriales son distintas y así un largo etcétera.

Sin embargo, para muchos especialistas, como Martín Vegas (2009), no habría distinción entre la LIJ y la literatura -alta literatura-, aunque podemos apreciar algún problema de apreciación en esta definición que sigue. El problema de fondo es que la LIJ no parece haberse abordado desde un punto de vista estético. Centrando la observación desde las cualidades intrínsecas de la literatura, no parece muy pertinente hablar de impacto en el público (es un fenómeno sociológico o económico); construcción temática (la característica fundamental de la novela es la libertad) y, sobre todo de transmisión de valores (de ello se encarga la estética del didactismo, que es una estética ${ }^{3}$ que engloba a una parte de la literatura, pero no a toda la literatura):

La LIJ tiene todos los ingredientes de la Literatura, es decir, comparte los rasgos que definen la literariedad del texto. Por tanto, la valoración de su calidad se mide por los mismos parámetros: impacto en el público, construcción temática, discurso, lenguaje, transmisión de valores etc. La cuestión es qué es lo que hace que una obra determinada sea literatura para jóvenes y la creada por ellos. En esta línea, Díaz-Plaja Taboada y Prats i Ripoll (1998) definen la LIJ como:

1. Literatura escrita por niños y jóvenes (con más valor psicopedagógigo que literario).

2. Literatura supuestamente destinada a los adolescentes.

3. Literatura de imaginación adaptada a la comprensión de la infancia y al mundo que interesa a los niños. (Martín Vegas, 2009: 280-281)

Entonces: ¿Cuáles son pues las características de la LIJ? ¿De dónde surgen las diferencias si es que las hay? ¿Qué razones podemos aducir para considerarla literatura o subliteratura?

En primer lugar, la LIJ está fuertemente marcada por ser un producto comercial ya hemos dicho que esto no tiene nada de malo-, el problema es cuando la literatura

\footnotetext{
${ }^{3}$ Para ahondar en esta tendencia estética es de especial utilidad la obra de Luis Beltrán Almería, ver bibliografía.
} 
se convierte en una serie de obras pensadas para un público en concreto. Y ello, ocasiona, en gran medida, que los autores pierdan gran parte de su libertad creadora para ajustarse a una serie de parámetros. La literatura también se atiene en gran medida a una serie de parámetros, pero de ahí precisamente que, para muchos, la literatura histórica o la literatura policíaca sea considerada subliteratura.

La LIJ, como producto comercial, tiene su espacio de ventas privilegiado en los centros escolares, salvo honrosas excepciones. Además, muchas de estas obras se piensan y construyen para servir a una serie de criterios, que poco o nada tienen que ver con cuestiones estéticas. Puesto que de negocio estamos hablando, debemos citar el importante peso económico de este tipo de literatura (aproximadamente el 10\% del mercado editorial ${ }^{4}$ ) y cómo, en ocasiones y como profesores, nos puede afectar, ya que editoriales de cierto peso nos pueden ofrecer algún tipo de compensación si elegimos tal o cual lectura. A veces podemos estar de acuerdo, pero en ocasiones, quizá sea preferible no escuchar ciertos cantos de sirena a la hora de hacer nuestras elecciones.

Teresa Colomer en una entrevista publicada en el año 2006 nos advierte de algunos de los peligros a los que, como docentes, nos debemos enfrentar cuando tratamos con la LIJ, en el fondo, el problema subyacente, es al que nos referimos, su opinión puede servir de conclusión a este epígrafe:

En un artículo suyo publicado en el 2000 (CLIJ, año 13, $n^{\circ}$ 130, set. 2000) usted advertía acerca de un "debilitamiento de la dimensión metafórica y simbólica de las obras, la pérdida de peso de la palabra y la escasa fuerza de las imágenes evocadas, en favor de otros elementos como la intriga argumental, la identificación del mundo creado con el lector y el desplazamiento de la experiencia estética hacia la parte ilustrada del libro”. ¿Cómo ha sido la evolución de estos asuntos en la producción editorial destinada a niños y jóvenes? ¿Qué cambios advierte y qué influencia ha ejercido al respecto la cibercultura?

- Esa advertencia provenía de una constatación sobre la producción actual. Muchos libros parecen descuidar la dimensión lingüística y literaria de las obras porque, en nuestras sociedades de consumo, los elementos visuales y de edición pueden ejercer un reclamo más efectivo para la venta de los libros. Fenómenos como la apuesta por la intriga o la identificación proyectiva pueden verse también en la edición adulta de los best-sellers, los libros regalo, los libros destinados a sectores concretos de la población (libros para mujeres maduras, para treintañeros, etc.). Los sistemas artísticos y de ficción de una sociedad son complejos y tienen múltiples círculos de producción y recepción. Hablamos de los libros infantiles como si fueran una unidad, pero su desarrollo implica también la formación de circuitos distintos. Los mediadores tienen que tener presentes esas categorías para elegir los libros según lo que desean hacer con ellos. La intriga argumental, por ejemplo, no tiene nada de

\footnotetext{
${ }^{4} \mathrm{http}$ //www.europapress.es/cultura/libros-00132/noticia-ventas-literatura-infantil-juvenilcrecen-114-pese-crisis-20100324180200.html (Consultado 28/09/2010)
} 
malo, y para crear hábitos lectores resulta muy efectiva, pero el lector no progresa en su capacidad de interpretación si no le ofrecemos también placeres más elaborados.

\subsection{Razón de ser de la LIJ. Características}

La LIJ es, sobre todo, un instrumento de trabajo bajo los parámetros de los currículos escolares. A través de la LIJ se trabajan, en teoría, los cuatro bloques de contenidos de los currículos: "Escuchar, hablar y conversar", "Leer y escribir", "Educación literaria" y "Conocimiento de lengua". Además, e igual de importante, es que estos libros desarrollen la Educación en valores democráticos $\mathrm{y}$, por supuesto, las competencias básicas, notablemente, la competencia en comunicación lingüística y la cultural y artística.

Este penúltimo apartado de la Educación en valores democráticos parece ser una de las piedras angulares de la LIJ, es decir, una serie de valores organizados en contenidos educativos que los alumnos que se deben tratar en la ESO desde todas las materias, para cumplir uno de los principales objetivos de esta educación, la formación de ciudadanos. El artículo 11 del currículo de la Comunidad Autónoma de Aragón ${ }^{5}$ (que adapta la Ley Orgánica 3 de mayo de Educación (LOE) al contexto de dicha comunidad) los recoge de la siguiente manera:

\section{Artículo 11. Educación en valores}

1. Atendiendo a los principios educativos esenciales, y en especial a la adquisición de las competencias básicas para lograr una educación integral, la educación en valores deberá formar parte de todos los procesos de enseñanza y aprendizaje, por ser uno de los elementos de mayor relevancia en la educación del alumnado.

2. La educación para la tolerancia, para la paz, la educación para la convivencia, la educación intercultural, para la igualdad entre hombres y mujeres, la educación ambiental, la promoción de la salud, la educación sexual, la educación del consumidor y la educación vial, que se articulan en torno a la educación en valores democráticos, constituyen una serie de contenidos que deberán integrarse y desarrollarse con carácter transversal en todas las materias del currículo y en todas las actividades escolares, pudiendo constituirse en elementos organizadores de los contenidos.

Por poner algunos ejemplos, la educación para la tolerancia, la paz y la convivencia se trata en obras que a menudo se leen en los centros escolares como Kerr, Cuando Hitler robó el conejo rosa. La educación intercultural se puede trabajar desde numerosas obras como en El caso de la cofradía de Ramón Acín o 18 inmigrantes y medio de Roberto Santiago. La educación para la igualdad, aparece en obras como Los escarabajos vuelan al atardecer de Gripe o, Barrotes de bambú de Terlow. La educación ambiental es un tema muy común, como muestra podemos

${ }^{5}$ Orden 9 de mayo de 2007:

http://www.educaragon.org/files/Orden\%20curr\%C3\%ADculo\%20Primaria.pdf 
señalar obras como Gata García de Pilar Mateos o de Sierra i Fabra: El cazador. La educación sexual es quizá el menos tratado al ser considerado un tema tabú. A pesar de ello, podemos citar la obra de Lienas, El diario de Carlota. La educación para la salud es quizá el tema que más en extenso se trate, en parte, por la enorme variedad de condiciones que podemos relacionar con este tema, podemos señalar ejemplos como Las chicas de alambre de Sierra i Fabra o Campos de fresas del mismo autor. La educación del consumidor, en especial en relación con los medios de comunicación aparece a menudo en la obra de Sierra i Fabra, en concreto, en Balada del siglo XXI. Por último, la educación vial toma protagonismo de múltiples formas, por ejemplo, a través de los dramáticos accidentes de tráfico en Voy a vivir de Tricker o Aún estoy vivo de Coué.

Todo ello, hace que podamos hablar de que una de las características de la LIJ es el didactismo, entendiendo como tal (Beltrán 2003: 51):

Dominio estético dogmático, fundado en la búsqueda utópica del bien supremo. $\quad$ El método didáctico consiste en el desarrollo de una conciencia (éthos). Y ese desarrollo admite tres orientaciones: confesional-rendición de cuentas, tratadista-ensayística y hermética. En ellas el lector se identifica con unas ideas, que encuentra en polémica con otras.

Más tarde, el mismo autor nos informa desde una perspectiva algo más práctica sobre las formas del didactismo, que entiendo es una de las estéticas principales de la novela juvenil, al fin y al cabo, se trata fundamentalmente de crear una conciencia:

Tres elementos constituyen el bagaje esencial del didactismo retórico: el polemismo la lucha con el otro-, la dignificación y la ausencia de personaje, que es también ausencia de fábula. Estos elementos se han ido preparando en el primer didactismo el didactismo predogmático-. En esta etapa los tres son débiles -especialmente la dignificación-. Esta debilidad se explica porque la utopía del primer didactismo es la utopía filosófica, el acceso a la verdad. Pero con la generalización de las escuelas y sus dogmas la utopía didáctica se transforma. La utopía filosófica es desplazada por la utopía retórica, el logro de la persuasión. A menudo, puede encontrarse en la Antigüedad una fórmula de transición entre ambas utopías, que se expresa en la fórmula "lo que persuade por su verdad". (Beltrán, 2002, 158).

Una gran parte de las novelas juveniles están pensadas de este modo y, desde luego, así son percibidas por las editoriales y el profesorado: como una herramienta de aprendizaje a varios niveles. Es decir, estamos ante una literatura que cumple una misión didáctica, por un lado, desde el punto de vista moral, por otro, desde el punto de vista comunicativo. El problema es que muchas de estas obras, han perdido en parte la esencia artística intrínseca en una obra literaria. Debido a esta razón, el público de la LIJ es limitado. Es cierto que cualquiera puede leer un libro de estas características, sin embargo, la propia editorial nos avisa de que está recomendado para personas de una determinada edad, además, estos libros se alojan en sellos y colecciones específicas, dirigidas sólo a un determinado público. 
En cualquier caso, adentrarnos en la lectura de estos libros, en la mayoría de los casos, supone enfrentarnos a situaciones y personajes que no suelen adaptarse a los gustos del público adulto, precisamente por las razones señaladas anteriormente, son obras concebidas para educar, para expresar y mostrar un pensamiento, heredero de la utopía, quizá, pero es que siempre estamos persiguiendo una utopía, quizá, uno de las razones del sistema educativo. Así lo expresa Cansinos (García, 2006: 84)

Esta heterogeneidad temática, que en sí misma no es contraproducente, ha lastrado muchas obras porque desde el principio han sido concebidas de modo oportunista, esto es, no como un objeto de arte en sí mismas, ni como respuesta a la sincera necesidad interior de un autor, sino como un medio para abordar en el aula los diferentes temas transversales recogidos en la última reforma educativa. Estas obras se convierten en "novelas documento" al servicio de la transmisión de una determinada información que interesa puntualmente a los jóvenes. Al mismo tiempo, este hecho ha propiciado un empobrecedor fenómeno de uniformidad temática y formal.

Otra de las razones para este desencuentro entre lectores adultos y jóvenes es que la temática de la LIJ suele ser cerrada, incluso algunos temas son tabúes (como por ejemplo el tema de la sexualidad o su variante educativa de la Educación sexual). Este fenómeno, es algo paradójico puesto que los jóvenes, grandes consumidores, en líneas generales, de productos audiovisuales, están más que acostumbrados a este tipo de temas (por poner un caso, las series en principio para adolescentes como Física o Química, tienen buenas dosis de sexualidad). Como ejemplo de una cierta adaptación de esta temática, podemos recordar parte de las obras de Sierra i Fabra, como Nunca seremos estrellas del rock o Campos de fresas. Como decimos, el tabú se va erosionando poco a poco, así lo reconoce Vásquez (2003), en referencia a la temática de la LIJ, incide en la importancia de que, poco a poco, este tipo de literatura añade nuevos temas que tradicionalmente no tenían cabida:

A pesar de que varios autores desarrollen un mismo tema, generalmente el enfoque resulta particular y diferente y las innovaciones formales permiten distinguir claramente el enfoque resulta particular y diferente y las innovaciones formales permiten distinguir claramente el aporte de cada uno de ellos. Además, se incorporan aquellos temas que tradicionalmente habían sido considerados como tabú o simplemente conflictivos: la muerte, el racismo, la injusticia social, la guerra, la crueldad, la incomunicación, el sexismo, la contaminación, la anorexia, el suicidio, la depresión etc. Lo importante es que estos temas son tratados como una concepción artística, libre de elementos que pretenden moralizar (Hendriks 1990: 14) y, por lo tanto, puesto únicamente al servicio de la naturaleza literaria de las obras.

En cuanto a los temas, podemos destacar como temáticas principales las que señala Tejerina (20045) en su estudio, si bien algunos pueden ser poco específicos o, lo más frecuente, es que en una obra se traten varios temas. Otro problema, fruto quizá del poco interés que ha recibido esta literatura por parte de la crítica literaria, es 
la confusión entre temáticas y géneros, así queda patente (quizá se pueda deber a que estos términos eran para una encuesta entre estudiantes) en la clasificación de Tejerina, donde se habla de: obras de "temas de mi edad", "Aventuras", "Amor", "Misterio", "Policíacos", "Terror", "Histórico", "Ciencia-ficción", "Fantasía", "Humor", "Problemas actuales", "Sexo", "Juegos de Rol", "Cómics", "Otros". Para Martín Vegas (2009: 281), los temas son: "Aventuras, vida cotidiana de niños y adolescentes, amor adolescente, fantasía, miedo e intriga donde los niñosadolescentes son héroes, búsqueda de identidad del protagonista para implicar al lector en la misma, arquetipos, etc."

Retomando esta clasificación, podemos hablar de otros temas muy habituales como son los problemas de amistad o amorosos; el descubrimiento de las relaciones sexuales; el contacto con las drogas; los problemas familiares; los problemas de salud o la relación de los jóvenes con nuevas tecnologías.

Sin embargo, si hemos dicho que la literatura para jóvenes debe adaptarse a sus intereses, gustos, cabe preguntarse si todos los potenciales lectores tienen los mismos intereses, algo como es lógico del todo imposible. De ahí, que una serie de criterios universales (tópicos de esta literatura) puedan ser señalados en una gran parte de las obras consideradas como LIJ, por ejemplo, en medio de una trama normalmente de misterio o policíaca donde las drogas juegan un papel fundamental, habrá casi siempre un amorío que finaliza, normalmente, con un besito o la promesa del mismo.

Se ha insistido en numerosas ocasiones sobre la importancia en la LIJ del fenómeno de identificación entre el lector y los personajes. Este fenómeno, universal en nuestras relaciones personales, en el mundo de la música, el cine o la publicidad, en lo literario y más superficial, queda patente en la edad de los personajes, la música que escuchan o las circunstancias que pueden vivir.

Sin embargo, más en profundidad, se puede analizar desde otros puntos de vista, como el sociológico, psicológico o desde lo estético. Tomando este último rasgo, destaca en la LIJ la aparición constante de la estética del patetismo y algunas de sus variedades, fundamentalmente, el patetismo sentimental. En su punto más básico, esta estética aparece para producir la identificación del lector con los personajes, o cuando menos, que el lector se equipare a ellos para compartir los sentimientos que los personajes expresan y que, de alguna manera los humaniza, y pone a la misma altura moral que al lector. El fenómeno literario del patetismo consiste en

construir un héroe, un pathos. Patetismo es heroificación, un método de elevación del personaje que hace de él un héroe. Si el patetismo suele reducirse al sentimentalismo, la heroificación está ausente del didactismo, como veremos después, y del humor, que constituye la réplica estética al patetismo.” (Beltrán, 2002: 64).

En este apartado, conviene recordar que la heroificación se da en un buen número de novelas modernas y no significa necesariamente que el personaje se convierta en un héroe en el sentido mítico o épico de la palabra. Por otra parte, y retomando las palabras de Beltrán, la heroificación en la novela juvenil tiene como objetivo fundamental el didactismo, entendido este en un sentido pedagógico muy básico que 
ya hemos explicado anteriormente y que no entra en contradicción con la anterior cita, y es que el mal ejemplo desencadena el bueno.

Como otra característica importante, podemos señalar que los personajes que solemos encontrar en este tipo de obras son prototípicos y, en la mayoría de los casos, muy planos. Creo que podríamos establecer sin muchas dificultades una tipología sobre los mismos o, que todavía sigue vigente en gran medida la tipología de actantes que podemos encontrar en la obra Morfología del cuento de Propp. Así, el esquema fundamental es un héroe, acompañado por un grupo de amigos que se enfrentan a un misterio desencadenado normalmente por una fuerza negativa. Bajo mi punto de vista, el gran éxito de Manolito Gafotas de Elvira Lindo, se debe a escapar, precisamente, de ese esquema de personajes y primar otra serie de valores, dejando un poco de lado la estética didáctica y patética para dar paso, por ejemplo, al humorismo.

Se habla en ocasiones de la poca calidad de este tipo de obras. Esta noción es injusta y, además, poco demostrable, puesto que se debiera hablar de una obra en concreto, además, y retomando la comparación entre literatura y subliteratura, no toda ella es desdeñable:

Cabe referirse, por supuesto, a la diferencia de calidad. Eso, siendo subjetivo, me parece muy importante, pues es el criterio básico para cualquier creación estética. Por supuesto, entre Pérez Galdós y Corín Tellado existe un abismo de calidad. Pero no hay que suponer, generalizando, que toda la subliteratura sea estéticamente ínfima. (Amorós, 2001: 199)

En cuanto a la calidad, puede tener mucho que ver el lenguaje utilizado y definido por Martín Vegas (2009: 281) como "sencillo, tono y nivel de lengua propio de niños y jóvenes". Por un lado, se simplifica al máximo, confundiendo en ocasiones, lenguaje comprensible con un público poco avispado. Una cosa es que se adapte el lenguaje, hecho poco acertado bajo mi punto de vista si nos atenemos a que el libro educa, enseña (vocabulario entre otras cosas) y es un instrumento de trabajo (debería mantener el viejo principio horaciano del "docere et delectare"). Esta adaptación también se da en cuanto a la construcción oracional, la mayor parte de nuestros alumnos entiende lo que lee, incluso frases subordinadas, y es que en ocasiones, la simplificación es alarmante.

Por otro lado, tampoco todos los alumnos hablan utilizando sartas infinitas de palabras groseras ni denominando a todo "rollo" o "movida", lo que supone, en definitiva, faltar a una de las máximas literarias fundamentales: la verosimilitud. El uso de este tipo de vocabulario, es doblemente incomprensible, primero porque crea una estandarización de este tipo de expresiones (nunca he leído, aunque bien puede ser culpa mía, que los jóvenes se llamen "co", algo muy usual en ciertas zonas de Aragón, ni "pisha o shosho", muy común en Cádiz) que no se ajusta a la realidad. Segundo, porque hace de los libros así redactados un elemento sujeto a periclitar en breve, las modas lingüísticas de este tipo desaparecen o varían con una enorme rapidez, lo que no hará sino hacer de ese libro, en principio, un producto con una fecha de caducidad muy temprana. 
Por otra parte, en lo que se refiere a la estructura de gran parte de estos libros, también peca de excesivamente simple, Martín Vegas (2009: 281), la define como "lineal, progresiva, estructura clásica (planteamiento de la situación-acción-problema, nudo y desenlace)". Los capítulos son en ocasiones tremendamente breves, es cierto que esta construcción favorece la lectura, la hace más rápida, pero en ocasiones, esto se traduce en un excesivo simplismo. La noción de brevedad no es válida a la hora de juzgar un libro, es cierto, pero tampoco a la hora de elegirlo, entre otras cosas, porque sabemos que si un libro atrapa al lector, poco importa su tamaño, pensemos, por ejemplo, en la cantidad de niños de este mundo que han devorado las aventuras de Harry Potter, no precisamente un libro breve.

Ocurre lo mismo con la trama narrativa, en la mayoría de los casos lineal, sin mayor complicación. Pensar que de ser de otra forma los alumnos se van a perder o no van a comprender la historia es infravalorarlos nuevamente puesto que están de sobra acostumbrados al lenguaje fílmico o al de los vídeo juegos, donde las historias no tienen por qué ser lineales. Como ejemplo llamativo de ruptura de la narración lineal, merece la pena contemplar El caso de la cofradía de Acín.

\section{CONCLUSIÓN}

Por todas estas razones, y tomando como marco explicativo la definición de Correa y Orozco que hemos reproducido anteriormente, creo que estamos en condiciones de afirmar que la LIJ puede adscribirse en lo que se ha definido anteriormente como "subliteratura". Por un lado, en muchas ocasiones, se pierde de vista que la literatura es un arte y se da prioridad a otra serie de valores como el oportunismo, el didactismo forzado o la repetición de esquemas que, por la razón que fuere, han resultado exitosos en otras obras. En muchas ocasiones, ello da lugar a una serie de serie de lugares comunes repetidos hasta la saciedad: chico de familia humilde metido en una trama de traficantes de drogas, chica dulce que lo intenta ayudar... Ello produce una serie de personajes recurrentes, muy a menudo, sin una psicología desarrollada, muy planos en definitiva, que acaban cumpliendo una serie de papeles muy próximos a las situaciones que define Propp en su archiconocida obra.

Sin embargo, todo ello no significa que no podamos utilizar o acudir a estas obras, más bien al contrario, sabemos que debemos hacerlo, además de por las razones que indica Amorós, por otras muchas que ya hemos ido señalando en estas páginas, fundamentalmente, el fomento de la lectura, y es que

La subliteratura [...] posee un interés sociológico absolutamente evidente, sin necesidad de más justificación; y, en ocasiones, un interés literario indiscutible. Si la obra literaria puede darnos un reflejo de la sociedad tan bueno o mejor que el historiador, psicólogo o sociólogo, no cabe duda de que la subliteratura puede hacerlo con mucha mayor nitidez, ofreciéndonos la escala de valores de una sociedad o de sus grupos, sin la transformación a que la hubiera sometido un creador de fuerte 
personalidad. En este sentido, el conocimiento de la subliteratura (sobre todo, por supuesto, de la que alcanza más éxito popular) puede ser un instrumento de gran utilidad para una historia de las mentalidades. (Amorós, 2001, 197)

Pero de nuevo, y hablando de la LIJ debemos hacer un esfuerzo por seleccionar las obras que pueden cumplir mejor nuestros propósitos como docentes, prestando especial atención al desarrollo de la competencia literaria y a la competencia en comunicación lingüística. Para ello, nuestro espíritu crítico, unido a nuestro esfuerzo lector, debe trabajar al máximo para evitar caer en la elección más fácil, más obvia pero no por ello mejor. Debemos estar atentos ante libros que se nos presentan como resultado del oportunismo o de la producción en "cadena" para cubrir unas expectativas de negocio. Probablemente, estos libros no serán ni mejores ni peores que otros, pero si perdemos de vista que los libros deben responder a una vocación artística y estética podemos estar incurriendo en un grave de error cuyas consecuencias no son fácilmente apreciables ni palpables pero de gran importancia para el sistema educativo y cultural, y es que de lo que se trata es de algo tan sencillo como ganar o perder lectores.

\section{REFERENCIAS BIBLIOGRÁFICAS}

AMORÓS, A. (1994): Subliteraturas, Barcelona, Ariel.

BELTRÁN, L. (2002): La imaginación literaria, Barcelona, Montesinos.

BELTRÁN, L. (2003): "Hacia una filosofía de la historia literaria", en RILCE 19.1, 51-59.

BELTRÁN, L. (2004): Estética y literatura, Madrid, Mare Nostrum.

BLOOM, H. (1995): El canon de occidente, Barcelona, Taurus.

CABESA, M. (2009): "Corín Tellado y los márgenes de la literatura", en Letralia, 208, abril. [En línea]: http://www.letralia.com/208/articulo01.htm [Consultado: 5 de septiembre de 2010]

CASTRO, V. y KLIBANSKI, M. (2006): Entrevista a Teresa Colomer. [En línea]: http://portal.educ.ar/noticias/entrevistas/teresa-colomer-hace-decadas-qu.php [Consulta: 10 de octubre de 2010]

CERRILLO, P. y GARCÍA PADRINO, J. (1996): Hábitos lectores y animación a la lectura, Murcia, Universidad de Castilla La Mancha.

CERRILLO, P. (2007): Literatura Infantil y Juvenil y educación literaria, Barcelona, Octaedro.

CORREA PÉREZ, A. y OROZCO TORRE, A. (2004): Literatura Universal, México, Pearson Educación.

MENDOZA FILlOLA, A. (coord.) (1998): Conceptos clave de didáctica de la lengua y la literatura, Barcelona, Universidad de Barcelona.

MENDOZA FILLOLA, A. (2002): "La renovación del canon escolar. La integración de la literatura infantil y juvenil en la formación literaria", en Actas del VI Congreso de la Sociedad Española de Didáctica de la Lengua y la Literatura: 
"El reto de la lengua en el siglo XXI", diciembre/2000. Sociedad Española de Didáctica de la Lengua y la Literatura, Universidad de Granada. [En línea]: http:/www.cervantesvirtual.com/servlet/SirveObras/91316152989597943532279 /index.htm [Consulta 5 de septiembre de 2010]

MORENO, V. (2003): "Los supuestos valores de la crítica", en CLIJ, 156, 28-36.

PROPP, V. (1985): Morfología del cuento, Madrid, Akal.

ROSAL, M. (2008): Con voz propia. Estudio y antología comentada de la poesía escrita por mujeres (1970-2005), Sevilla, Renacimiento.

SULLA, E. (1998): El canon literario, Madrid, Arco Libros.

TEJERINA LOBO, I. (): Lecturas y lectores en la ESO, Una Investigación Educativa, Consejería de Educación de Cantabria.

TEJERINA LOBO, I. (2004): "Grandes tendencias, autores y obras de la literatura infantil y juvenil española en el umbral del siglo XXI", en Varios Autores, Romanistické Studie. Studia Romanistica, Ostravská Universita Ostrava, Filozofická Faculta, 217, cislo 4, 201-209. [En línea]:

http://www.biblioteca.org.ar/libros/132663.pdf [Consulta: 23 de agosto de 2010]

TEJERINA LOBO, I. (2004): "Los cien libros del siglo: El canon literario y la literatura infantil y juvenil", en Revista de la Asociación de Amigos del Libro infantil y juvenil, núm. 4,17-25.

VÁSQUEZ, (2003): "La actual narrativa infantil y juvenil española", en Filología y Lingüística, núm. XXIX (1), 61-81. 